Portland State University

PDXScholar

\title{
Cheers to Haptic Sensations and Alcohol Consumption: How Glassware Weight Impacts Perceived Intoxication and Positive Emotions
}

\author{
Courtney Szocs \\ Portland State University, courtne@pdx.edu \\ Dipayan Biswas \\ University of South Florida \\ Adilson Borges \\ NEOMA Business School
}

Follow this and additional works at: https://pdxscholar.library.pdx.edu/busadmin_fac

Part of the Advertising and Promotion Management Commons, and the Marketing Commons Let us know how access to this document benefits you.

\begin{abstract}
Citation Details
Courtney Szocs, Dipayan Biswas, and Adilson Borges, "Cheers to Haptic Sensations and Alcohol Consumption: How Glassware Weight Impacts Perceived Intoxication and Positive Emotions," Journal of the Association for Consumer Research 1, no. 4 (October 2016): 569-578.
\end{abstract}

This Article is brought to you for free and open access. It has been accepted for inclusion in Business Faculty Publications and Presentations by an authorized administrator of PDXScholar. Please contact us if we can make this document more accessible: pdxscholar@pdx.edu. 


\title{
Cheers to Haptic Sensations and Alcohol Consumption: How Glassware Weight Impacts Perceived Intoxication and Positive Emotions
}

\author{
COURTNEY SZOCS, DIPAYAN BISWAS, AND ADILSON BORGES
}

\begin{abstract}
People often consume alcohol as a means of emotional control. More specifically, people frequently consume alcohol to enhance positive feelings (e.g., happiness) and reduce negative feelings (e.g., stress, tension). The results of two field studies and one laboratory study showed that holding the volume of alcohol consumed constant and varying the haptic (i.e., weight) sensations individuals experience during consumption can influence these emotional responses and also perceived intoxication. Specifically, we manipulated haptic weight sensations by varying the weight of the cup/container (e.g., champagne flute) alcohol was consumed from and showed that consuming champagne from lighter (vs. heavier) flutes leads to enhanced positive feelings, reduced negative feelings, and increased perceived intoxication.
\end{abstract}

V

hether to induce positive feelings or to offset negative feelings, people often consume alcohol as a means of emotional control (Cooper et al. 1995). In that regard, alcohol consumption is frequently motivated by the desire to enhance positive feelings, such as enjoyment and pleasure, as well as to offset negative feelings, such as stress, depression, and anxiety (Cox and Klinger 1988; Smith, Abbey, and Scott 1993; Piasecki et al. 2014). One poll even shows that over $65 \%$ of consumers use alcohol to relax and to offset negative feelings related to stress or tension (BBC News 2012).

While alcohol consumption is often motivated by the desire to regulate positive and negative feelings, volume of alcohol consumed is not a perfect predictor of these feelings. Rather, these feelings are often a function of perceived rather than actual consumption volume (Lang et al. 1975; Maisto, Conners, and Sachs 1981; Sher 1985; Moss, Yao, and Maddock 1989). Moreover, studies with nonalcoholic beverages show that perceived consumption is subject to perceptual biases. For instance, Raghubir and Krishna (1999) showed that individuals use visual cues related to the height of the glass that a beverages is consumed from to assess perceived volume of the container and also perceived consumption volume. This leads consumers to believe that elongated (i.e., taller) glasses contain a greater volume of a beverage than shorterwider glasses but to believe that they consume more from shorter-wider glasses (Raghubir and Krishna 1999). In addition to using visual factors to assess volume, factors related to haptics (i.e., the sense of touch) also influence volume perceptions. Specifically, Krishna (2006) has shown that when visual cues related to the height of the glass are unavailable, individuals use the circumference of the glass perceived through grasping with the hand to judge volume. Collectively, these studies highlight the malleability of perceived consumption to perceptual biases.

In this research, we built on the facts that (1) individuals consume alcohol as a means of emotional control (i.e., to enhance positive and reduce negative feelings), (2) these positive and negative feelings can be related to perceived rather than actual consumption, and (3) studies with nonalcoholic beverages have shown that perceptual factors can influence perceived consumption. We examined how one perceptual factor related to haptics (i.e., weight sensations) subconsciously influenced these two key motivators of alcohol consumption as well as perceived intoxication. We investigated the influence of haptic sensations by varying the weight of the cup/container the alcohol was consumed from, and we addressed the following research questions: Holding actual volume of consumption constant, would consuming from a lighter (vs. heavier) cup/container influence positive or negative feelings associated with alcohol consumption or perceived intoxication?

Courtney Szocs (courtne@pdx.edu) is assistant professor of marketing, Portland State University, Portland, OR 97201. Dipayan Biswas (dbiswas@usf.edu) is professor of marketing, University of South Florida, Tampa, FL 33620. Adilson Borges (adilson.borges@reims-ms.fr) is IRC Processor Professor of Marketing, NEOMA Business School, Reims Cedex, France.

JACR, volume 1, number 4. Published online August 29, 2016. http://dx.doi.org/10.1086/688219

(c) 2016 the Association for Consumer Research. All rights reserved. 2378-1815/2016/0104-0004\$10.00 
From prior research, the answer to this question is not clear. Research on how the weight of bowls, containers, and spoons influences perceptions related to the food being consumed has yielded seemingly inconsistent results. Specifically, in one study, Piqueras-Fiszman et al. (2011) varied the weight of bowls that foods were served in, and they found that consumers tend to assimilate the properties of the food with the weight of the bowls so that foods in heavier bowls are perceived as more dense and more intense in flavor than the same foods served in lighter-weight bowls. In a similar vein, Piqueras-Fiszman and Spence (2012) varied the weight of the container that yogurt was served in and also found that consumers assimilate judgments about the food with the weight of the container, so that yogurt served in heavier containers was expected to be more dense and more satiating than yogurt served in lighter containers. While these studies show assimilation effects between the weight of the bowl/container and properties of the food, Harrar and Spence (2013) found contrast effects, whereby yogurt consumed from heavier spoons was perceived as less dense than yogurt consumed from lighter-weight spoons. Collectively, these studies attest to the importance of the haptic property weight in influencing consumers' perceptions; however, it is not clear how or why cup/container weight would influence positive and negative emotional responses or perceived intoxication. The aim of this research was to take a step toward resolving the inconsistencies in prior work. We also wanted to gain a better understanding of the role of haptics in influencing alcohol related effects on emotional states.

Understanding how haptic sensations influence perceived intoxication and the positive and negative feelings associated with alcohol consumption also contributes to the broader body of literature on sensory marketing. To elaborate, weight is one of four haptic properties individuals rely on when evaluating objects (Klatzky and Lederman 2002), with temperature, texture (i.e., roughness/smoothness), and compliance (i.e., hardness/softness) being the other three. In that regard, prior research shows that these haptic properties play an important role in food/beverage evaluations. Specifically, Krishna and Morrin (2008) focused on hardness/firmness and showed that beverages are perceived as better tasting when served in firm (vs. flimsy) containers. Piqueras-Fiszman and Spence (2012) focused on the haptic property of texture and showed that "biscuits" (i.e., cookies) are perceived as harder and crunchier when served in a rough-textured (vs. smooth-textured) container. Biswas, Szocs, et al. (2014) examined food compliance (hardness vs. softness) and texture (roughness vs. smoothness) and showed that food that is soft or has a smooth texture is perceived as higher in calories when compared to the same food that is hard or has a rough texture. There has been less work examining the other two haptic properties (i.e., temperature and weight). Furthermore, as noted previously, prior work related to weight has yielded inconsistent results.

Finally, this work contributes to the literature on consumers' responses to alcohol consumption. Despite the fact that alcohol consumption is increasing worldwide (SABC News 2014; Dwyer-Lindgren et al. 2015), there has been hardly any academic research, especially in the marketing literature, on the influences and behavioral consequences of alcohol consumption. Extant work has focused on the influence of advertising on consumers' attitudes and behavioral intentions (see Hovland [2015] for a review) and the influence of anti-drinking messages (Agrawal and Duhachek 2010) and health message frames on drinking intentions (Duhachek, Agrawal, and Han 2012). We know of no field studies on alcohol consumption in the marketing literature. This research takes an important step in that regard.

In addition to these theoretical implications, our research also has a number of important practical implications. First, in demonstrating that haptic sensations associated with cup/ container weight influence consumers' emotional responses and perceived intoxication level, we pave the way for marketers, bar/restaurant managers, consumers, and regulators to use cup/container weight strategically. Specifically, bar/ restaurant managers have considerable flexibility in determining the cup/container alcoholic beverages are consumed from. Our research suggests that managers might strategically utilize different glassware to influence patrons' emotional responses and perceived intoxication levels. In a similar vein, many alcohol manufacturers provide bars/restaurants with specialty labeled glassware (e.g., Stella Artois beer chalices) for serving their products. Thus, it is possible that manufacturers might be able to strategically design specialty glassware to influence consumers' perceptions. Consumers who are at risk for alcohol-related diseases might also be able to use haptic sensations strategically. Specifically, individuals vary in their sensitivity to the effects of alcohol (Schuckit 1994; Schuckit and Smith 2000). Individuals with low sensitivity to alcohol consumption tend to be more responsive to alcohol-related cues (Bartholow, Henry, and Lust 2007) and at a higher risk for alcohol-related diseases. Finally, regulators and policy makers can use the insights provided by our studies to safeguard consumer interests. Next, we review literature related to placebo effects of perceived consumption as well as work on weight perception to build a framework for our hypotheses. Then we discuss two field 
experiments and a controlled lab study that tested our hypotheses.

\section{THEORETICAL BACKGROUND Placebo Effects of Perceived Consumption}

As noted previously, the responses that stem from alcohol consumption are often related to perceived rather than actual consumption volume. Thus, factors that influence perceived consumption play a critical role in driving the emotional and behavioral responses that are associated with alcohol consumption (Lang et al. 1975; Maisto et al. 1981; Sher 1985; Moss et al. 1989). For instance, in one reported study, individuals who believed they had drunk alcohol were more aggressive than individuals who believed they had only drunk tonic water, irrespective of what they actually consumed (Lang et al. 1975). Along similar lines, individuals who believed they had drunk a greater volume of alcohol engaged in more risk-taking behavior when driving (McMillen, Smith, and Wells-Parker 1989). These findings highlight potential placebo effects of perceived rather than actual alcohol consumption.

The current research departed from these prior studies by examining how varying the weight of cups/containers influences perceived intoxication and the positive and negative feelings associated with alcohol consumption. So how might cups/containers of different weights lead to placebo effects of perceived consumption and ultimately perceived intoxication and emotional responses?

Prior research shows that perceived weight is often used as a heuristic for perceived volume due to a strong positive correlation between weight and volume (Ellis and Lederman 1993). Individuals do not directly experience the weight of the beverages they consume. This is because beverages are served in some sort of container or cup. To assess weight, individuals would have to assess the change in the weight of the cup/container before and after consumption. Thus, individuals should subconsciously use the change in the weight of the cup/container (from when it is full to when it is empty) as a heuristic for volume and therefore perceived consumption. Perceived consumption would in turn drive positive and negative feelings and perceived intoxication. Before discussing specific predictions about how perceived weight change would influence emotional responses and perceived intoxication, we first discuss weight perception in general.

\section{Weight Perception}

Weight is a relative judgment, meaning that when evaluating the weight of an object (i.e., the target) an individual would compare the object to some reference point (Flana- gan et al. 2008; Buckingham, Cant, and Goodale 2009). The reference point can be a function of the material (Ellis and Lederman 1999), size (Stevens and Rubin 1970), or color (De Camp 1917) of the target or the evaluator's expectations/ prior experience (Ellis and Lederman 1998). In the context of the present research, the focal weight judgment would involve assessing the change in the weight of the cup/container before and after consumption and using this weight change as a heuristic for perceived consumption volume. Thus, perceived consumption volume would be assessed by comparing the weight of the empty cup/container (i.e., the target) to the weight of the full cup/container (i.e., the reference point)

Prior research shows that the weight of the reference point can influence judgments of the target (De Camp 1917; Stevens and Rubin 1970; Ellis and Lederman 1998, 1999). More specifically, the magnitude of the difference between the weight of the target and the weight of the reference point can lead to assimilation or contrast effects. Contrast effects typically emerge when there is a large difference between the weight of the target and the weight of the reference point, and assimilation effects emerge when there is a small difference between the weight of the target and the weight of the reference point (Sherif, Taub, and Hovland 1958). The key issue for our work was how the magnitude of the weight change (from when the cup was full/ before consumption to when it was empty/after consumption) would vary as a function of the cup weight and how the weight change would influence emotional responses and perceived intoxication.

\section{Weight Perception and Heavy (vs. Light) Cups/Containers}

When a fixed volume of a beverage is consumed from a heavier (vs. lighter) cup/container, there would be a smaller difference in perceived weight between the full and empty container. For example, in the case of a heavy champagne flute (weighing $145 \mathrm{~g}$ ), a difference in weight of 37.5 grams due to consumption of the champagne would seem relatively minor. In contrast, for a lighter flute (weighing $110 \mathrm{~g}$ ), a difference in weight of 37.5 grams due to consumption of the champagne would seem relatively larger. That is, there would be a difference of $25.86 \%$ in the former and $34.09 \%$ in the latter, with the latter being $31.82 \%$ higher than the former.

A large difference between the target and the reference point should lead to contrast effects, and a small difference between the target and the reference point should lead to assimilation effects (Sherif et al. 1958). With the lighter cup/container, there would be a relatively larger change in 
weight after the beverage is consumed. Thus, individuals would experience a contrast between the weight of the full cup/container and the weight of the empty cup/container. Individuals would be more likely to notice this weight change, subconsciously assume they drank a greater volume of the beverage, and ultimately experience greater perceived intoxication and stronger emotional responses. In contrast, with a heavier cup/container, the change in weight associated with consuming the beverage would be relatively smaller, making it more difficult to determine the volume consumed. Thus, with heavier cups/containers, individuals would assimilate the weight of the empty cup with the weight of the full cup, subconsciously assume they had drunk a smaller volume of the beverage, and experience a lower level of perceived intoxication and weaker emotional responses. Formally stated:

H1: Consuming alcoholic beverages from lighter (vs. heavier) weight cups/containers leads to (a) enhanced positive feelings, $(b)$ reduced negative feelings, and (c) increased perceived intoxication.

\section{STUDY 1. THE EFFECTS OF CHAMPAGNE FLUTE WEIGHT ON POSITIVE EMOTIONAL RESPONSES AT CHAMPAGNE HOUSES Design, Participants, and Procedure}

Study 1 tested hypothesis $1 \mathrm{a}$ and the effects of cup/container weight in influencing emotional responses, with the help of a one-factor between-subjects design field experiment with two manipulated conditions (flute weight: lighter vs. heavier).

The study was conducted at champagne tasting events at a champagne house (of a major champagne manufacturer), in collaboration with the company management. The study was conducted across several days and time slots. The experimental condition (i.e., flute weight) was randomly varied for each time slot. Flute weight was varied in this way to eliminate the chance that someone in one condition might pick up or hold a flute from the other experimental condition. Visitors to the champagne tasting events were given 3.75 centiliters $(1.27 \mathrm{oz}$.) of complimentary champagne (that weighed $37.5 \mathrm{~g}$ ) in a flute that weighed either 145 grams or 110 grams empty, depending on the experimental condition. As mentioned before, 37.5 grams is $25.86 \%$ of 145 and $34.09 \%$ of 110 , and the latter percentage is $31.82 \%$ higher than the former. It should be noted that both cham- pagne flutes looked identical, but they had different weights. After consuming the champagne, a research assistant collected the flutes, and attendees were asked to complete a short survey. The key dependent variable, perceived happiness, was measured by asking participants to rate how happy they felt ( $1=$ not at all happy, $7=$ very happy).

One hundred and five champagne house patrons expressed willingness to participate in this study $(55.2 \% \mathrm{fe}-$ male; $M_{\text {age }}=36.48$ years), representing approximately $79 \%$ of the individuals who were approached to participate.

\section{Results and Discussion}

The results of a one-way ANOVA with flute weight as the independent variable and perceived happiness as the dependent variable showed that patrons who consumed the champagne from the lighter (vs. heavier) flute felt marginally happier $\left(M_{\text {lighter }}=5.77\right.$ vs. $M_{\text {heavier }}=5.37 ; F(1,103)=$ 3.099, $p<$.09). Thus, hypothesis $1 \mathrm{a}$ is supported.

The results of study 1 showed that consuming from a light flute can enhance the positive feelings (i.e., happiness) associated with alcohol consumption. As with almost any field study, study 1 had high external validity, but we had less control over the experimental manipulations. For example, in the study, participants were socializing, as is the case in any champagne tasting event, which in turn might have reduced the effects of the haptic sensations. In other words, these extraneous factors might have contributed to the effects being only marginally significant. Next, in study 2 , we replicated the results of study 1 in a more controlled laboratory setting, and we also tested hypothesis $1 \mathrm{c}$ (the influence of flute weight on perceived intoxication).

\section{STUDY 2. THE EFFECTS OF CHAMPAGNE FLUTE WEIGHT ON POSITIVE EMOTIONAL RESPONSES AND PERCEIVED INTOXICATION}

Study 2 was a between-subjects experiment with two conditions (flute weight: lighter vs. heavier). University personnel and students were invited to a laboratory to participate in a study on champagne evaluations. In order to participate in the study, individuals had to be over the legal drinking age in the country where the study was conducted (i.e., age 18) and willing to drink champagne. Participants were given 3.75 centiliters ( 1.27 oz.) of champagne in a heavy or light flute. They were instructed to consume the entire contents of the flute. Once they had consumed the champagne, a research assistant collected the flute, and participants were moved to another section of the room, where 
they completed the survey. The key dependent measures were perceived happiness ( $1=$ not at all cheerful, $7=$ very cheerful) and perceived intoxication ( $1=$ not at all intoxicated, 7 = very intoxicated).

Sixty individuals participated in this study; at the time of filling out the study survey, one individual indicated a very high level of impairment. The data from this individual were removed, leaving a final sample of $59\left(M_{\text {age }}=34.56\right.$; $47.5 \%$ female). It should be noted that retaining versus removing the data from this individual does not change the overall pattern of results.

\section{Results and Discussion}

A one-way ANOVA with flute weight as the independent variable and happiness as the dependent variable revealed that individuals who consumed from the lighter flute felt happier than individuals who consumed from the heavier flute $\left(M_{\text {lighter }}=5.86\right.$ vs. $M_{\text {heavier }}=5.13 ; F(1,57)=5.66$, $p<.05)$. Additionally, individuals who consumed from the lighter flute also felt relatively more intoxicated $\left(M_{\text {lighter }}=\right.$ 1.52 vs. $\left.M_{\text {heavier }}=1.13 ; F(1,57)=4.32, p<.05\right)$.

Overall, the results of study 2 replicated the results of study 1 in a more controlled laboratory setting. The results also supported hypothesis $1 c$, whereby haptic weight sensations significantly influenced perceived intoxication. Next, study 3 built on these effects by showing that flute weight offsets the negative emotional responses associated with consuming alcoholic beverages. Additionally, study 3 also examined a boundary condition to the effects of cup/container weight.

\section{STUDY 3. MODERATING EFFECT OF NONCONTINUOUS HAPTIC SENSATIONS}

The purpose of study 3 was to examine a boundary condition to the effects demonstrated in study 1 and study 2 . In our prior studies, the haptic sensations associated with the weight of the cup were continuous; that is, participants held on to the champagne flute until they consumed the entire contents of the flute. Specifically, in study 1 , champagne house patrons held flutes of champagne while they consumed the champagne and then gave the empty flutes to a research assistant. In study 2, participants consumed champagne in a room without the option to set the flutes down. Hence, they had to hold the flutes until they had consumed the sample and the research assistant collected the flute. In study 3 , we examined how the effects of haptic sensations on emotional responses would change when haptic sensations were not continuous. So, how would noncontinuous haptic sensations influence emotional responses associated with alcohol consumption?

One theory is that when haptic-related weight sensations are interrupted, individuals may not notice the weight change from the full to the empty glass. This would lead to an attenuation of the effects of cup weight on emotional responses associated with alcohol consumption. However, a competing theory is that individuals might habituate to the weight of the cup when sensations are continuous (Biswas, Labrecque, et al. 2014). If habituation occurs, then making the haptic sensations noncontinuous could negate it. This could make the perceived lack of weight change with the heavy cups more salient, leading to an amplification of the effects of cup weight on emotional responses. In light of these possible conflicting predictions, we did not propose a formal hypothesis about how noncontinuous weight sensations would influence the effect of cup weight on emotional responses.

\section{Design, Participants, and Procedure}

Study 3 was a 2 (flute weight: lighter vs. heavier) $\times 2$ (haptic sensations: continuous vs. noncontinuous) betweensubjects field experiment. The study was conducted at social events at a business school. The study took place on multiple days and continuity/noncontinuity of haptic sensations varied by day, so that sensations were continuous some days and noncontinuous the other days. Flute weight was varied randomly on all days. Event attendees who agreed to participate were given 1.27 ounces of complimentary champagne in a heavy or light flute depending on the experimental condition. Continuity of haptic sensations was manipulated through the absence (continuous condition) or presence (noncontinuous condition) of cocktail tables. Specifically, in the noncontinuous haptic sensations conditions, cocktail tables were set up throughout the event so that participants could set their champagne flutes down between sips. In the continuous haptic sensations conditions, there were no cocktail tables to set the flutes on; hence, participants had to hold the flute continuously between sips.

After consuming the flute of champagne, participants filled out a survey. We assessed whether haptic sensations would offset negative emotional responses (i.e., stress, tension) by asking participants to rate how relaxed they felt $(1=$ not at all relaxed, $7=$ very relaxed). Participants were also asked to rate the taste of the champagne $(1=$ not at all delicious, 
7 = very delicious) and indicate how frequently they consumed champagne $(1=$ rarely, $7=$ very often $)$.

One hundred and forty-one event attendees agreed to participate in this study ( $49.6 \%$ female; $M_{\text {age }}=21.63$ years). This represented approximately $73 \%$ of all attendees who were approached to participate. It should be noted that the study was conducted in a country where the legal drinking age is 18 .

\section{Results}

Since study 1 was conducted at tasting events at a champagne house, and in study 2 participants were recruited to participate in a study on champagne, it is reasonable to assume that participants in these studies enjoyed champagne and were familiar with it. However, given that study 3 was conducted in a different field context, we could not make these assumptions. Consequently, in study 3 , the perceived taste and frequency of champagne consumption were included as covariates in the analysis.

The results of a 2 (flute weight) $\times 2$ (haptic sensation continuity) ANCOVA with perceived taste and frequency of champagne consumption as covariates revealed a marginally significant interaction effect $(F(1,133)=3.22, p<.08)$ and a marginally significant main effect of flute weight $(F(1,133)=3.57, p<.07)$ on perceived relaxation. The main effect of continuity of haptic sensations was not significant $(F(1,133)=.09, p=.77)$. Follow-up tests showed that when the haptic sensations were continuous, consuming from a lighter weight flute led to greater perceived relaxation $\left(M_{\text {lighter }}=6.00\right.$ vs. $M_{\text {heavier }}=5.45 ; F(1,135)=3.72$, $p=.056)$. However, when the haptic sensations were not continuous, there was no difference in perceived relaxation based on flute weight $\left(M_{\text {lighter }}=5.78\right.$ vs. $M_{\text {heavier }}=5.71$; $F(1,135)=.052, p=.82)$. Overall the results of study 3 showed that continuity of haptic sensations represents a boundary condition to the effects of haptic sensations on emotional responses. Interestingly, some of the effects in this study were also marginally significant, as in study 1 , which was also a field study. This provides further support for our contention that the presence of several extraneous variables in field settings might have weakened the observed effects, compared to what we observed in our lab study, where the effects were much stronger.

\section{GENERAL DISCUSSION}

This research examined the effects of the haptic property of weight on emotional responses and perceived intoxication, variables that are often associated with alcohol con- sumption. We examined the effects of weight by varying the weight of cups/containers that beverages were consumed from and found that consuming from lighter cups/containers (e.g., champagne flutes) enhanced the positive feelings and offset the negative feelings that are often associated with alcohol consumption and also increased perceived intoxication. We theorized that the effects of weight on emotional responses and perceived intoxication were driven by assimilation and contrast between the weight of the beverage and the weight of the container. Specifically, we theorized that with heavy containers, the weight of the cup after consumption assimilates with the weight of the cup before consumption leading to underestimation of the amount consumed. In contrast, with lighter containers, the weight of the container after consumption contrasts with the weight of the container before consumption leading individuals to relatively overestimate the amount of alcohol consumed. The results of two field studies and one laboratory study demonstrated the effects of the haptic property of weight on perceived intoxication and the emotional responses associated with alcohol consumption. Specifically, in study 1 , a field study at a champagne house, we varied the weight of the champagne flute that visitors sampled from and showed that sampling from lighter flutes enhances positive emotional responses associated with alcohol consumption. Then, in study 2, we replicated these effects in a controlled lab setting and also showed that consuming from lighter flutes leads to enhanced perceived intoxication. Finally, in study 3 , we showed that sampling from lighter (vs. heavier) flutes offsets the negative emotional responses associated with alcohol consumption. In addition, the results of study 3 also identified a boundary condition to the effects of weight on emotional responses by showing that the effects are attenuated when the haptic sensations are not continuous.

\section{Conceptual and Practical Implications}

The findings of this research contribute to several literature streams. First, our findings help resolve the apparent inconsistencies in the literature related to how weight influences product perceptions. Specifically, our findings suggest that the assimilation effects observed in prior studies (e.g., Piqueras-Fiszman et al. 2011; Piqueras-Fiszman and Spence 2012) might be a function of the fact that the change in weight due to consumption in these studies would have been very small, whereas the contrast effects observed in other studies (e.g., Harrar and Spence 2013) occurred when the weight change due to consumption would have been relatively larger. Thus, our findings can possibly help reconcile 
these seemingly contradictory findings by showing that whether assimilation or contrast effects are observed when weight is varied is a function of the relative size of the weight change associated with consumption.

Our findings also contribute to the broader body of literature on sensory marketing. This research shows that subconscious sensory factors can have a profound influence on consumers' judgments and decisions (Krishna 2012). In showing that haptics related to the weight of the cup/container beverages are consumed from can influence emotional responses associated with alcohol consumption, we contribute to the literature by showing that sensory factors can possibly be a surrogate for consumption in terms of influencing emotional responses.

In addition, our findings contribute to the literature on product versus experience effects. Research in this stream shows that experiences make individuals happier than products (Van Boven and Gilovich 2003; Van Boven 2005). We held the focal product (i.e., alcoholic beverages) constant and showed that varying sensory experiences associated with consuming products can influence emotional responses and perceived intoxication levels. This suggests that haptic sensations associated with the consumption medium can indeed contribute to the consumption experience.

Individuals consume alcohol as a means of emotional control (Cooper et al. 1995). However, in some cases, individuals consume alcohol to the point that it can become destructive (e.g., they become addicted; Vohs and Baumeister 2009). Given that our findings suggest that haptic weight sensations can increase perceived intoxication and enhance emotional responses that are associated with alcohol consumption, it is possible that such sensations could become surrogates for consumption. Specifically, it is possible that individuals might be able to obtain some of the responses they desire from consumption by drinking from cups/containers of certain weights. Thus, an individual who desires to increase perceived intoxication or enhance positive emotions might be able to consume less while drinking from a lighter glass. It is also possible that these haptic sensations might be useful in treating addiction. Specifically, haptic sensations related to weight might be able to satiate or at least reduce cravings. This prediction is consistent with research in the domain of self-regulation that shows that when a desire is satiated, its strength weakens (De Wall, Baumeister, and Vohs 2008).

It is also important to note that excessive levels of alcohol consumption have adverse outcomes in the form of aggressive and violent behavior and other negative conse- quences (Zhang, Welte, and Wieczorek 2002). Hence, if perceived intoxication and the emotional responses associated with alcohol consumption can be achieved with a lower volume of alcohol, this can be beneficial. As the results of our studies showed, drinking from a lighter weight cup/container can be more beneficial in terms of increasing perceived intoxication and achieving enhanced positive and reduced negative emotional responses.

In addition to these conceptual implications, the findings of our work also have important practical implications. One of the key drivers of alcohol consumption relates to the emotional responses that are associated with consumption (Cox and Klinger 1988; Smith et al. 1993; Piasecki et al. 2014). However, these positive and negative feelings are not always related to consumption volume (Lang et al. 1975; Maisto et al. 1981; Sher 1985; Moss et al. 1989), suggesting that the emotional responses consumers seek from drinking alcohol might be achieved through means other than actual consumption volume. In this research, we identified one such alternative means of achieving these emotional responses in terms of the weight of the cup/container alcohol is consumed from.

The results of our studies also suggest that champagne houses, restaurants, and beverage manufacturers should be mindful when selecting the cups/containers (e.g., glasses, flutes) beverages are served in, since container weight can have unintended consequences in terms of influencing perceived intoxication as well as the emotional responses associated with alcohol consumption. More specifically, a high proportion of wine and champagne sales occur at tasting and sampling events (Folwell and Grassel 1995). At these tasting events marketers have complete control over the type of glass/flute used. In addition, some alcoholic beverages, such as beer, are consumed directly from a bottle, and marketers have direct control over the weight of the bottle. Similarly, marketers of alcohol brands might be able to influence the types of cups/containers used for serving their drinks at bars and restaurants (e.g., Stella Artois is often served in a chalice that contains the logo).

The findings of our studies also have important implications for consumers. Individuals vary in their sensitivity to alcohol (Schuckit 1994; Schuckit and Smith 2000). Moreover, individuals who exhibit low sensitivity are not only less sensitive to the effects of alcohol; they are also more attentive (Shin et al. 2010) and responsive to alcohol-related cues (Bartholow et al. 2007), and they are at higher risk for alcohol-related diseases (Fleming and Bartholow 2014). Building on the idea that individuals who are at the highest risk 
for alcohol-related diseases are also more sensitive to alcoholrelated cues, it stands to reason that these individuals should be the most likely to experience the effects of haptic sensations. This is important, since it suggests the potential for haptic sensations to be used as a surrogate for consumption in terms of eliciting optimal emotional responses.

\section{Limitations and Opportunities for Future Research}

We proposed that the effects of haptic sensations on perceived intoxication and emotional responses were driven by assimilation and contrast effects. However, we did not provide direct empirical evidence demonstrating this proposed process. It is possible that other processes, apart from assimilation/contrast, are influencing the results observed in our studies. For instance, it is possible that individuals were more worried about dropping the flute when they consumed from heavy (vs. light) flutes and that this sense of worry detracted from their experience. It is also possible that holding heavier flutes elicited motor effects. Future research should delve deeper into the process driving the observed effects.

We focused on the effect of haptic (weight sensations) on the emotional responses associated with alcohol consumption. There are other, nonalcoholic beverages that are consumed for the emotional responses they induce (e.g., tea, energy drinks). Would the effects of haptic, weight-related sensations hold with nonalcoholic beverages? The results of two additional laboratory studies that we conducted suggest that the effects may not hold for nonalcoholic beverages. Specifically, we varied the weight of disposable cups by unobtrusively attaching weights to the bottom of the cups (i.e., heavy condition) or not attaching weights to the bottom of the cups (i.e., light condition). Then, we had participants ( $n=54$ in study 1 and $n=66$ in study 2 ) consume a fixed quantity of green tea. The results of study 1 showed no significant difference in emotional responses (happiness: $M_{\text {lighter }}=4.96$ vs. $M_{\text {heavy }}=5.0 ; F(1,52)=.011, p=.92$; relaxation: $M_{\text {lighter }}=4.39$ vs. $\left.M_{\text {heavy }}=4.62 ; F(1,52)=.31, p=.58\right)$. Similarly, the results of study 2 also showed no significant differences in emotional responses (happiness: $M_{\text {lighter }}=4.72$ vs. $M_{\text {heavy }}=5.15 ; F(1,64)=2.52, p=.12$; relaxation: $M_{\text {lighter }}=$ 4.31 vs. $\left.M_{\text {heavy }}=4.50 ; F(1,64)=.32, p=.58\right)$. These results suggest that our effects might only hold for alcoholic beverages.

It is also possible that the effects of haptic-related weight sensations only hold when certain consumption goals are active. Specifically, at a champagne house, in a laboratory study where individuals know they will be sampling champagne, or a social event, different goals would be activated than during a laboratory experiment with nonalcoholic beverages. It is possible that certain emotional responses would be more likely to emerge when hedonic goals are active. Consistent with this idea, prior research shows that the influence of sensory factors is dependent on the goals that are activated (Mishra, Mishra, and Masters 2012). Moreover, champagne consumption is often associated with celebrations. It is not clear if sampling champagne would activate any such celebration-related goals. Also, it should be noted that the effects of lighter cups/containers might be especially influential for champagne, since there is a congruency between the lightness of the beverage and the weight of the glass, whereas container weight might be less influential when individuals consume "heavier" beverages (e.g., beer, red wine, whiskey).

Champagne was the only alcoholic beverage used in our studies. In study 1 , we used champagne because that was the only beverage served at the champagne house, making it a logical choice. A limitation of our research is that we did not use other alcoholic beverages in study 2 or study 3. Future research should examine how varying the weight of beer mugs, wine glasses, and shot glasses influences consumers' responses.

Finally, as noted previously, individuals vary in their sensitivity to alcohol (Schuckit 1994; Schuckit and Smith 2000), and individuals with low alcohol sensitivity tend to be especially sensitive to alcohol-related cues (Bartholow et al. 2007). Thus, it is likely that the effects of haptics on emotional responses and perceived intoxication would be stronger for individuals with low alcohol sensitivity. In our studies, we did not measure alcohol sensitivity. Future research should examine the moderating effects of this individual difference.

In conclusion, using alcohol as a means of emotional control has the potential for serious costs, including poor sleep quality, long-term damage to the body, and elevated risk of accidents. Our work found that a low-cost, noninvasive feature of the vessel that holds the alcohol can make people feel happier, more relaxed, and indeed perceive higher intoxication - all without the potential harms related to actually imbibing.

\section{REFERENCES}

Agrawal, Nidhi, and Adam Duhachek (2010), "Emotional Compatibility and the Effectiveness of Anti-drinking Messages: A Defensive Processing Perspective on Shame and Guild," Journal of Marketing Research, 47 (April), 263-73. 
Bartholow, Bruce D., Erika A. Henry, and Sarah A. Lust (2007), "Effects of Alcohol Sensitivity on P3 Event-Related Potential Reactivity to Alcohol Cues," Psvchology of Addictive Behaviors, 21 (4), 555-63.

$B B C$ News (2012), "Two Thirds 'Turn to Drink' to Relax in the Evening," BBC News, http://www.bbc.com/news/health-18724115.

Biswas, Dipayan, Lauren Labrecque, Donald Lehmann, and Ereni Markos (2014), "Making Choices While Smelling, Tasting, and Listening: The Role of Sensory (Dis)similarity When Sequentially Sampling Products," Journal of Marketing, 78 (1), 112-26.

Biswas, Dipayan, Courtney Szocs, Aradhna Krishna, and Donald R. Lehmann (2014), "Something to Chew On: The Effects of Oral Haptics on Mastication, Orosensory Perception, and Calorie Estimation," Journal of Consumer Research, 41 (August), 261-73.

Buckingham, Gavin, Jonathan S. Cant, and Melvyn A. Goodale (2009), "Living in a Material World: How Visual Cues to Material Properties Affect the Way That We Lift Objects and Perceive Their Weight," Journal of Neurophvsiology, 102 (6), 3111-18.

Cooper, M. Lynne, Micheal R. Frone, Marcia Russell, and Pamela Mudar (1995), "Drinking to Regulate Positive and Negative Emotions: A Motivational Model of Alcohol Use," Journal of Personalitv and Social Psvchology, 69 (5), 990-1005.

Cox, Miles W., and Eric Klinger (1988), "A Motivational Model of Alcohol Use," Journal of Abnormal Psychology, 97 (2), 168-80.

De Camp, J. E. (1917), "The Influence of Colour on Apparent Weight," Journal of Experimental Psychologv, 2 (5), 347-70.

De Wall, C. Nathan, Roy F. Baumeister, and Kathleen D. Vohs (2008), "Satiated with Belongingness? Effects of Acceptance, Rejection and Task Framing on Self-Regulatory Performance," Journal of Personality and Social Psychology, 95 (6), 1367-82.

Duhachek, Adam, Nidhi Agrawal, and Dahee Han (2012), "Guilt versus Shame: Coping, Fluency, and Framing in the Effectiveness of Responsible Drinking Messages," Journal of Marketing Research, 49 (December), 928-41.

Dwyer-Lindgren Laura, Abraham D. Flaxman, Marie Ng, Gillian M. Hansen, Christopher J. L. Murray, and Ali H. Mokdad (2015), "Drinking Patterns in US Counties from 2002 to 2012," American Journal of Public Health, 23 (April), e1-e8.

Ellis, Robert R., and Susan J. Lederman (1993), "The Role of Haptic versus Visual Volume Cues in the Size-Weight Illusion," Perception and Psychophysics, 53 (3), 315-24.

(1998), "The Golf-Ball Illusion: Evidence for Top Down Processing in Weight Perception," Perception, 27 (2), 193-202.

- (1999), "The Material-Weight Illusion Revisited," Perception and Psychophvsics, 61 (8), 1564-76.

Flanagan, J. Randall, Jennifer P. Bittner, and Roland S. Johansson (2008), "Experience Can Change Distinct Size-Weight Priors Engaged When Lifting Objects and Judging Their Weights," Current Biologv, 18 (22), 1742-47.

Fleming, Kimberly A., and Bruce D. Bartholow (2014), "Alcohol Cues, Approach Bias, and Inhibitory Control: Applying a Dual Process Model of Addiction to Alcohol Sensitivity," Psvchologv of Addictive Behaviors, 28 (1), 85-96.

Folwell, Raymond J., and Mark A. Grassel (1995), "How Tasting Rooms Can Help Sell Wine," Advertising and Promotion, 11-14.

Harrar, Vanessa, and Charles Spence (2013), "The Taste of Cutlery: How the Taste of Food Is Affected by the Weight, Size, Shape and Colour of Cutlery Used to Eat It," Flavour, 2 (21), 1-12.

Hovland, Roxanne (2015), "Alcoholic Beverage Advertising: An Integrative Interdisciplinary Review," Journal of Current Issues and Research in Advertising, 36 (1), 88-114.
Klatzky, Roberta L., and Susan J. Lederman (2002), "Touch," in Experimental Psychology, ed. A. F. Healy and R.W. Proctor, Vol. 4 in Handbook of Psychology, ed. I. B. Weiner (editor-in-chief), New York: Wiley, 147-76.

Krishna, Aradhna (2006), "Interaction of the Senses: The Effect of Vision versus Touch on the Elongation Bias," Journal of Consumer Research, 32 (March), 557-66.

(2012), "An Integrative Review of Sensory Marketing: Engaging the Senses to Affect Perception, Judgment and Behavior," Journal of Consumer Psychology, 22 (3), 332-51.

Krishna, Aradhnam, and Maureen Morrin (2008), "Does Touch Affect Taste? The Perceptual Transfer of Product Container Haptic Cues," Journal of Consumer Research, 34 (April), 807-18.

Lang, Alan R., Daniel J. Goeckner, Vincent J. Adesso, and G. Alan Marlatt (1975), "Effects of Alcohol on Aggression in Male Social Drinkers," Journal of Abnormal Psychology, 84 (5), 508-18.

Maisto, Stephen A., Gerard J. Connors, and Paul R. Sachs (1981), "Expectation as a Mediator in Alcohol Intoxication: a Reference Level Model," Cognitive Therapv and Research, 5 (1), 1-18.

McMillen, David L., Stephen M. Smith, and Elisabeth Wells-Parker (1989), "The Effects of Alcohol, Expectancy and Sensations Seeking on Driving," Addictive Behavior, 14 (4), 477-83.

Mishra, Arul, Himanshu Mishra, and Tamara M. Masters (2012), "The Influence of Bite Size on Quantity of Food Consumed: A Field Study," Journal of Consumer Research, 38 (5), 791-95.

Moss, Howard B., Jeffrey K. Yao, and John M. Maddock (1989), "Responses by Sons of Alcoholic Fathers to Alcoholic and Placebo Drinks: Perceived Mood, Intoxication, and Plasma Prolactin," Alcoholism: Clinical and Experimental Research, 13 (2), 252-57.

Piasecki, Thomas M., Lynne M. Cooper, Phillip K. Wood, Kenneth J. Sher, Saul Shiffman, and Andrew C. Heath (2014), "Dispositional Drinking Motives: Associations with Appraised Alcohol Effects and Alcohol Consumption in an Ecological Momentary Assessment Investigation," $\underline{\underline{P S v-}}$ chological Assessment, 26 (2), 363-69.

Piqueras-Fiszman, Betina, Vanessa Harrar, Jorge Alcaide, and Charles Spence (2011), "Does the Weight of the Dish Influence Our Perception of Food?" Food Quality and Preference, 22 (8), 753-56.

Piqueras-Fiszman, Betina, and Charles Spence (2012), "The Influence of the Feel of Product Packaging on the Perception of the Oral-Somatosensory Texture of Food," Food Quality and Preference, 26 (January), 67-73.

Raghubir, Priya, and Aradhna Krishna (1999), "Vital Dimensions in Volume Perception: Can the Eye Fool the Stomach?” Journal of Marketing Research, 36 (3), 313-26.

SABCNews (2014), "Alcohol Consumption Is on the Rise across the Globe," http://www.sabc.co.za/news/a/814b628043fbd9ee84a8b4866b9bf97e /Alcohol-consumption-is-on-the-rise-across-the-globe-20140513.

Schuckit, Mark A. (1994), "Low Level of Response to Alcohol as a Predictor of Future Alcoholism," American Journal of Psychiatry, 151 (2), 184-89.

Schuckit, Mark A., and T. L. Smith (2000), "The Relationships of a Family History of Alcohol Dependence, a Low Level of Response to Alcohol and Six Domains of Life Functioning to the Development of Alcohol Use Disorders," Journal of Studies on Alcohol, 61 (6), 827-35.

Sher, K. J. (1985), "Subjective Effects of Alcohol: The Influence of Setting and Individual Differences in Alcohol Expectancies," Journal of Studies on Alcohol and Drugs, 46 (2), 137-46.

Sherif, Muzafer, Daniel Taub, and Carl I. Hovland (1958), "Assimilation and Contrast Effects of Anchoring Stimuli on Judgments," Journal of Experimental Psychology, 55 (2), 150-55. 
Shin, Eunsam, Joseph B. Hopfinger, Sarah A. Lust, Erika A. Henry, and Bruce D. Bartholow (2010), "Electrophysiological Evidence of AlcoholRelated Attentional Bias in Social Drinkers Low in Alcohol Sensitivity," Psychology of Addictive Behaviors, 24 (3), 508-15.

Smith, Mary Jo, Antonia Abbey, and Richard O. Scott (1993), "Reasons for Drinking Alcohol: Their Relationship to Psychosocial Variables and Alcohol Consumption," Substance Use and Misuse, 28 (9), 881-908.

Stevens, Joseph C., and Lee L. Rubin (1970), "Psychophysical Scales of Apparent Heaviness and the Size-Weight Illusion," Perception and Psychophysics, 8 (4), 225-30.
Van Boven, Leaf (2005), "Experientialism, Materialism and the Pursuit of Happiness," Review of General Psychology, 9 (2), 132-42.

Van Boven, Leaf, and Thomas Gilovich (2003), "To Do or To Have? That Is the Question," Journal of Personality and Social Psychology, 85 (6), 1193-1202.

Vohs, Kathleen, and Roy F. Baumeister (2009), "Addiction and Free Will," Addiction Research and Theorv, 17 (3), 231-35.

Zhang, Lening, John Welte, and William W. Wieczorek (2002), “The Role of Aggression-Related Alcohol Expectancies in Explaining the Link between Alcohol and Violent Behavior," Substance Abuse and Misuse, 37 (4), 457-71. 